\title{
Palliative management of severe ovarian hyperstimulation syndrome: Two cases
}

\author{
Davut Güven*, Mukaddes Demir, İdris Koçak, Cazip Üstün \\ Department Obstetrics and Gynecology, 19 Mayls University School of Medicine, Samsun, Turkey
}

\begin{tabular}{|c|c|}
\hline \multicolumn{2}{|c|}{ ARTICLE INFO } \\
\hline \multicolumn{2}{|c|}{ Article History } \\
\hline Received & 05 / 07 / 2011 \\
\hline Accepted & 29 / 07 / 2011 \\
\hline \multicolumn{2}{|c|}{ * Correspondence to } \\
\hline \multicolumn{2}{|c|}{ Davut Güven } \\
\hline \multicolumn{2}{|c|}{ Cumhuriyet Mah. Atatürk Bulvarı 11. sokak } \\
\hline \multicolumn{2}{|c|}{ No:1 Bahadır Apartmanı Daire No:6 } \\
\hline \multicolumn{2}{|c|}{ Samsun/Turkey } \\
\hline e-mail: da & ven@yahoo.com \\
\hline
\end{tabular}

\begin{abstract}
The Ovarian Hyperstimulation Syndrome (OHSS) is characterised by a cystic enlargement of the ovaries and an acute fluid shift from the intravascular to the third space, which may result in ascites, pleural infusions, pericardial infusion and even generalised oedema. Although there are a lot of treatment modalities concerning OHSS, palliative care still remains as a basic and effective way of treatment as well as our main approach. J. Exp. Clin. Med., 2011; 28:120-121
\end{abstract}

Keywords:

OHSS

Ascites

Paracentesis

Infertility

Palliative management

IVF complication

C 2011 OMU All rights reserved

\section{Introduction}

Infertility is a common problem, with an overall median prevalence of $9 \%$. This prevalence appears to be similar in both the developed and less-developed parts of the world. About $56 \%$ of people actually seek medical help and $22 \%$ receive medical care. On the basis of the population, 72.4 million people are currently infertile; of these, approximately 40.5 million are seeking infertility medical care(Veerle Vloeberghs et al.,2009).

The Ovarian Hyperstimulation Syndrome was first described by Rabau in 1967 . OHSS is characterised by a cystic enlargement of the ovaries and an acute fluid shift from the intravascular to the third space, which may result in ascites, pleural infusions, pericardial infusion and even generalised oedema. This fluid shift is caused by an increase in vascular permeability and neoangiogenesis(Rabau et al.,1997).

Ovarian hyperstimulation syndrome (OHSS) is an iatrogenic complication of Ovarian stimulation(OS) occurring during the luteal phase or early pregnancy. The OHSS is a serious and potentially life-threatening physiologic complication, classically encountered in patients who undergo controlled ovarian hyperstimulation $(\mathrm{COH})$ cycles. The mortality rate related to OS is very low and was estimated by Brinsden et al.,(1995) to occur in $1 / 400,000$ to $1 / 500,000$ cycles of OS. Serour et al., (1998) reported one mortality owing to hepato- renal failure in 3500 cycles. The syndrome is typically associated with regimens of exogenous gonadotropins but also can be seen, albeit rarely, during administration of clomiphene citrate for ovulation induction (Joseph et al., 2000).

The most frequently used classification, proposed by Golan (Table 1), is based on the use of ultrasonography to quantify ovarian enlargement and ascites (Golan et al.,1989).

Table 1. Classification of ovarian hyperstimulation syndrome (OHSS)

\begin{tabular}{|l|l|}
\hline Mild & $\begin{array}{l}\text { Grade 1: abdominal distension and discomfort } \\
\text { Grade 2: grade 1 + nausea, vomiting and/diarrhea } \\
\text { enlarged ovaries 5-12 cm }\end{array}$ \\
\hline Moderate & Grade 3: grade 2 + ultrasound evidence of ascites. \\
\hline Severe & $\begin{array}{l}\text { Grade 4: grade 3 + clinical evidence of ascites and/or } \\
\text { hydrothorax and breathing difficulties } \\
\text { Grade 5: grade 4 + hemoconcentration, increase blood } \\
\text { viscosity, coagulation, abnormality and diminished } \\
\text { renal perfusion. }\end{array}$ \\
\hline
\end{tabular}

Note: Based on the system of Golan and colleagues (Golan et al,1989). 


\section{Cases}

\section{Case 1}

A 28 years old primigravida patient of which pregnancy was achieved with invitro fertilization(IVF) due to male factor, admitted to our clinic complaining of bloating and shortness of breath. According to last menstrual period (LMP) pregnancy was 4 weeks 2 days and USG showed considerable enlargement of the right ovary, measuring 104x102 mm, along with ascites and pleurel effusion. Laboratory results were as follows; Hb: $13.3 \mathrm{~g} / \mathrm{dl}, \mathrm{WBC}$ : $15 \mathrm{k} / \mathrm{ul}$, Htc: 37.9 fl, AST: 29 U/1, ALT: $18 \mathrm{U} / 1$, BUN: $9.8 \mathrm{mg} / \mathrm{dl}, \mathrm{Cr}: 0.5 \mathrm{mg} / \mathrm{dl}$. The electrolytes'( sodium, potassium, chlorine, calcium ) and the albumin and total protein levels and coagulation parameters were normal. Patient was hospitalized and following consecutive USG scans ascites started to disappear, ovaries turned to their normal size and a triplet gestation was visualized. Ascites and pleurel effusion disappeared and ovaries turned to normal size 15 days after hospitalization. Gestational sacs were visualized five days after hospitalization. The patient was hospitalized for 20 days. During follow up patient was delivered with Csection on her 36 th week. Two male babies weighing $2800 \mathrm{~g}$ and $1960 \mathrm{~g}$ and a female baby weighing $2880 \mathrm{~g}$ were delivered with no complications in all the babies and the mother.

\section{Case 2}

A 27 years old primigravida patient of which triplet pregnancy was achieved with IVF due to male factor was hospitalised because of severe OHSS. Laboratory results were as follows; Hb: 10.6 g/dl, WBC: 8.3 k/ul, Htc:43.3 fl, AST: 24 U/1, ALT: $25 \mathrm{U} / \mathrm{l}, \mathrm{BUN}$ : $6.7 \mathrm{mg} / \mathrm{dl}, \mathrm{Cr}: 0.6 \mathrm{mg} / \mathrm{dl}$. The electrolytes'( sodium, potassium, chlorine, calcium ) and the albumin and total protein levels and coagulation parameters were normal. USG showed enlargement of both ovaries, measuring 102x97 $\mathrm{mm}$ left and 120x105mm right, along with ascites. IV albumin was ordered and laboratory results, especially electrolytes, were closely monitored and replaced when necessary.Paracentesis was performed two day after hospitalization. Two Paracentesis had to be performed due to abdominal distension and shortness of breath. Second paracentesis was performed after two day. The paracentesis performed by USG guide. $1000 \mathrm{ml}$ fluid was discharged every paracentesis. Patient was discharged after becoming normal in both clinical findings and USG and 20 days after the hospitalized. During follow up, C-section was performed on her 33th week because of Premature Rupture of Membranes (PROM). Three female babies weighing $1860 \mathrm{~g}, 1650 \mathrm{~g}$ and $1450 \mathrm{~g}$ were delivered.Three babies were healty.

\section{Discussion}

OHSS is a complication of Controlled Ovarian Hyperstimulation $(\mathrm{COH})$ which is widely used, deserves acute diagnosis and treatment.

The primary approach in the prevention of OHSS involves identification of risk factors, individualized ovarian stimulation protocols, judicious administration of gonadotropins, and careful monitoring of follicular development and serum E2 level (Veerle Vloeberghs et al., 2009; Jack Yu Jen Huang et al.,2010) Whelan and Vlahos asserted that all physicians who prescribe medications with the potential to cause OHSS are obligated to know the risk factors, prevention strategies, staging, and treatment. The treatment algorithms for OHSS have centered historically on inpatient management of fluid status (Veerle Vloeberghs et al, 2009; Rabau et al., 1997; Smith et al., 2009). Patients who present with respiratory compromise secondary to massive ascites should undergo ultrasound,guided paracentesis with care taken to avoid ovarian cyst rupture (Veerle Vloeberghs et al., 2009; Martin et al., 1994).

Paracentesis should be performed under ultrasound guidance to avoid puncture of vascular ovaries distented by large luteal cysts. The optimal volume of fluid that can be removed at one occasion is not established.The removal of large volumes of protein-rich ascitic fluid may lead to the rapid accumulation of additional ascitic fluid and subsequent protein depletion, since proteins are lost from the intravascular compartment. Paracentesis will relieve pulmonary compromise not only by reducing compression on the diaphragm but also by resolving the hydrothorax (Martin et al., 1994; Whelan III et al., 2000; Veerle Vloeberghs et al., 2009).

Although there are a lot of treatment modalities concerning OHSS, palliative care still remains as a basic and effective way of treatment as well as our main approach.

\section{REFERENCES}

Brinsden, P.R., Wada, I., Tan, S.L., Balen, A., Jacobs, H.S., 1995. Review: diagnosis, prevention and management of ovarian hyperstimulation syndrome. Br. J. Obstet. Gynaecol. 102, 767772.

Golan, A., Ron-El, R., Herman, A., Weinraub, Z., Soffer, Y., Caspi, E., 1967. Ovarian hyperstimulation syndrome: an update review Obstet Gynecol. Surv. 44, 430-440.

Huang, J.Y.J., Rosenwaks, Z., 2010. Preventive Strategies of Ovarian Hyperstimulation Syndrome J. Exp. Clin. Med. 2, 53-62.

Whelan III, J.G., Vlahos, N.F., 2000. The ovarian hyperstimulation syndrome Fertil Steril. 73-75.

Smith, L.P., Hacker M.R., Alper M.M., 2009. Patients with severe ovarian hyperstimulation syndrome can be managed safely with aggressive outpatient transvaginal paracentesis. Fertil Steril. 92, 6.

Rabau, E., David, A., Serr, D.M., 1997. Mashiach S, Lunenfeld B. Human menopausal gonadotropins for anovulation and sterility Am. J. Obs. Gyn. 98, 92-98.

Martin, R.A., Edraki, B., Robert, L., 1994. Ovarian hyperstımulation syndrome in the emergency department: A case report. J. Emerg. Med. 12, 481-484.

Serour, G.I., Aboulghar, M., Mansour, R., Sattar, M.A., Amin, Y., Aboulghar, H., 1998. Complications of medically assisted conception in 3,500 cycles. Fertil Steril. 70, 638-642.

Vloeberghs, V., Peeraer, K., Pexsters, A., D’Hooghe, T., 2009. Ovarian hyperstimulation syndrome and complications of ART. Best Pract. Res. Cl. Ob. 23, 691-709. 